\title{
Synthesis of Polymers with Adamantane Amino Derivatives as Pendant Groups
}

\author{
Eri Yoshida, ${ }^{\dagger}$ Takashi TsuchiYa, and Koji Katayama \\ Department of Polymer Science and Engineering, Kyoto Institute of Technology, \\ Goshokaido-cho, Matsugasaki, Sakyo-ku, Kyoto 606-8585, Japan
}

(Received April 22, 1998)

\begin{abstract}
Radical polymerizations of $N$-(tricyclo[3.3.1.1 $\left.1^{3,7}\right]$ decane-1-yl)4-vinylbenzylamine (Ad0) and $N$-(tricyclo[3.3.1.1 $\left.{ }^{3,7}\right]$ decane-1-yl-methyl)4-vinylbenzylamine (Ad1) were conducted in bulk under nitrogen. The polymerizations of Ad0 and Ad1 proceeded at the vinyl groups to give polymers with adamantane amino derivatives as pendant groups. The polymerization of $\mathrm{Ad} 0$ gave the polymers without any crosslinked product, although a partially or completely crosslinked polymer was obtained from the polymerization of Adl at high temperature. Thermal stability of poly(Ad0) and poly(Adl) was excellent, and the stability of poly(Ad1) was much higher than that of poly(Ad0). The copolymerizations of Ad0 and Ad1 with styrene and methyl methacrylate (MMA) were also performed by $2,2^{\prime}$-azobis(isobutyronitrile) (AIBN) at $80^{\circ} \mathrm{C}$. The copolymers had similar feed ratios of monomers to styrene or MMA.
\end{abstract}

KEY WORDS Adamantane Amino Derivatives / Styrene / Methyl Methacrylate / Radical Polymerization / Random Copolymers / Thermal Stability /

Adamatane, discovered in petroleum, has attracted considerable attention because its derivatives show various bioactivities. The derivatives with amino and with amide groups have greater antiviral activity than those with other functional groups. These activities are, for instance, fungicidal, repellent, and herbicidal for $N, N$ alkyl-adamantanecarboxamide. ${ }^{1}$ Clinical investigators have found prophylactic effects of 1-adamantanamine and its hydrochloride salt toward influenza A virus strains, ${ }^{2}$ and therapeutic effects in patients suffering from Parkinson's disease. ${ }^{3}$ Inhibition of rubella, ${ }^{4}$ Rous sarcoma, ${ }^{5,6}$ and Esh sarcoma viruses has also been reported. Some publications have already been released on the immobilization of the amino and amide adamantane derivatives in polymers, for obtaining polymeric drugs with controlled release. These publications concern radical polymerizations of methacrylate and methacrylamide derivatives of adamantanamine. ${ }^{7}$ It is expected that monomers with bulky pendant groups such as adamantyl show low reactivity for polymerizing, because the groups prevent the growing polymer chain end from reacting with the monomers. Steric hindrance of the bulky group causes formation of oligomers and polymers with low molecular weights. In this study, we prepared two monomers of vinyl benzylamino derivatives from 1-adamantanamine and from 1-adamantanemethylamine. Benzylamino derivatives of adamantane have the greatest activiral activities among other amino derivatives with adamantane moiety. ${ }^{8}$ This paper describes the synthesis of polymers with adamantane benzylamine derivatives as pendant groups through the radical polymerizations of the two monomers, $N$-(tricyclo[3.3.1.1 $\left.1^{3,7}\right]$ decane-1-yl)4-vinylbenzylamine (Ad0) and $N$-(tricyclo[3.3.1.1 $\left.1^{3,7}\right]$ decane-1-yl-methyl)4-vinylbenzylamine (Ad1). The reactivity and thermal stability of the resulting polymers are described.

\section{EXPERIMENTAL}

\section{Measurements}

IR spectra were recorded with a JASCO FT/IR-5300 Fourier transfer infrared spectrometer. ${ }^{1} \mathrm{H}$ NMR spectra were obtained with a Bruker ARX-500 NMR spectrometer and ultraviolet (UV) spectra were also obtained with a Shimadzu UV-2500PC UV-VIS recording spectrophotometer. Differential scanning calorimetry (DSC) spectra were obtained with a Mac Science DSC-3100. Thermogravimetric analyses (TGA) spectra were recorded with a Shimadzu thermal analyzer DT-30. Gas chromatography (GC) was performed with a Shimadzu GC-6A. Gel permeation chromatography (GPC) was performed with a Tosoh HLC-802A instrument equipped with a Tosoh CP-8000 chromato processor. Two polystyrene gel columns of Tosoh TSK gel $\mathrm{G}^{2} 000 \mathrm{H}_{8}$ and $\mathrm{G} 2000 \mathrm{H}_{8}$ were used with tetrahydrofuran (THF) as the eluent at $42^{\circ} \mathrm{C}$.

\section{Materials}

4-Vinylbenzaldehyde was prepared as previously reported. ${ }^{9}$ Benzene was purified by refluxing on sodium for several hours and distilled over sodium. Ether was purified by refluxing on sodium for several hours and distilled over sodium just before use. Commercial grade styrene was washed with aqueous alkaline solution and water, and distilled over calcium hydride. Methyl methacrylate (MMA) was distilled over calcium hydride. 2,2'-Azobis(isobutyronitrile) (AIBN) was recrystallized from methanol. 1,1'-Azobis(cyclohexanecarbonitrile) was recrystallized from ethanol. 1-Adamantanamine, 1-adamantanemethylamine, $t$-butylcatecol, and di-tbutyl peroxide were used without further purification. Extrapure grade lithium aluminum hydride and anhydrous magnesium sulfate were used without further purification.

\footnotetext{
+ To whom correspondence should be addressed.
} 
$N-\left(\right.$ Tricyclo $\left[3.3 \cdot 1 \cdot 1^{3,7}\right]$ decane-1-yl $) 4$-vinylbenzylamine (AdO)

A solution of 4-vinylbenzaldehyde $(6.57 \mathrm{~g}, 49.7 \mathrm{mmol})$, 1 -adamantanamine $(8.28 \mathrm{~g}, 54.7 \mathrm{mmol}), t$-butylcatecol $(5 \mathrm{mg})$, and anhydrous magnesium sulfate (18.0 g, $0.149 \mathrm{~mol})$ in benzene $(120 \mathrm{~mL})$ was heated for $24 \mathrm{~h}$ under reflux with azeotropic removal of water. After the solution was cooled, it was washed with water, evaporated under reduced pressure and dried in vacuo for several hours to give the product of $11.2 \mathrm{~g}$. A solution of this product of $11.2 \mathrm{~g}$ in ether $(80 \mathrm{~mL})$ was added dropwise at room temperature over 30 min under nitrogen, to ether $(30 \mathrm{~mL})$ suspended with lithium aluminum hydride $(1.61 \mathrm{~g}, 42.3 \mathrm{mmol})$. The solution was heated at $50^{\circ} \mathrm{C}$ for $4 \mathrm{~h}$. The solution was washed with water, evaporated under reduced pressure and dried in vacuo for several hours to give $10.3 \mathrm{~g}$ of $\mathrm{Ad} 0$ as white crystals. The product was purified by repeated flush column chromatography. Ad0: ${ }^{1} \mathrm{H}$ NMR $\left(\mathrm{CDCl}_{3}\right) \delta 1.66(6 \mathrm{H}$, $\mathrm{dd}, J=14,25 \mathrm{~Hz}$ adamantyl $\left.\mathrm{CH}_{2}\right), 1.73(6 \mathrm{H}$, s, adamantyl $\left.\mathrm{CH}_{2}\right), 2.09(3 \mathrm{H}, \mathrm{s}$, adamantyl $\mathrm{CH}), 3.75(2 \mathrm{H}, \mathrm{s}$, $\left.\mathrm{CH}_{2}-\mathrm{NH}\right), 5.20,5.72\left(2 \mathrm{H}, \mathrm{d}, J=11,18 \mathrm{~Hz}\right.$, vinyl $\left.\mathrm{CH}_{2}\right)$, $6.70(1 \mathrm{H}, \mathrm{dd}, J=11,18 \mathrm{~Hz}$, vinyl $\mathrm{CH}), 7.31(2 \mathrm{H}, \mathrm{d}$, $J=8 \mathrm{~Hz}, \mathrm{Ar} \mathrm{CH}(\mathrm{C}-2,6)), 7.36(2 \mathrm{H}, \mathrm{d}, J=8 \mathrm{~Hz}, \mathrm{Ar} \mathrm{CH}$ $(\mathrm{C}-3,5)) .{ }^{13} \mathrm{C} \mathrm{NMR}\left(\mathrm{CDCl}_{3}\right) \delta 29.6$ (adamantyl C-3, 5, 7), 36.9 (adamantyl C-4, 6, 10), 42.9 (adamantyl C-1, 2, 8, 9), $44.9\left(\mathrm{CH}_{2}-\mathrm{NH}\right), 113.4\left(\mathrm{CH}_{2}=\mathrm{CH}\right), 126.3(\mathrm{Ar} \mathrm{C}-3$, 5), $128.6(\mathrm{Ar} \mathrm{C}-2,6), 136.2\left(\mathrm{CH}_{2}=\mathrm{CH}\right), 136.8(\mathrm{Ar}, \mathrm{C}-1$, 4). IR ( $\left.\mathrm{KBr}, \mathrm{cm}^{-1}\right) 3260,3084,3019,2899,2845,1628$, $1564,1510,1451,1150,992 . m / z=267.20 . \mathrm{mp}=44.0^{\circ} \mathrm{C}$.

\section{$N$-(Tricyclo[3.3.1.1 $\left.1^{3,7}\right]$ decane-1-yl-methyl $) 4$-vinylbenzyl- amine (Adl)}

The monomer of Ad1 was prepared in the same way as Ad0. A solution of 4-vinylbenzaldehyde $(0.582 \mathrm{~g}$, $4.405 \mathrm{mmol})$, 1-adamantanamine $(0.800 \mathrm{~g}, 4.84 \mathrm{mmol})$, $t$-butylcatecol $(1 \mathrm{mg})$, and anhydrous magnesium sulfate $(1.59 \mathrm{~g}, 13.2 \mathrm{mmol})$ in benzene $(15 \mathrm{~mL})$ was heated for $24 \mathrm{~h}$ under reflux with azeotropic removal of water. After being cooled, the solution was washed with water, evaporated under reduced pressure and dried in vacuo for several hours to give the product of $1.16 \mathrm{~g}$. A solution of this product of $1.16 \mathrm{~g}$ in ether $(5 \mathrm{~mL})$ was added dropwise at room temperature over $30 \mathrm{~min}$ under nitrogen, to ether $(6 \mathrm{~mL})$ suspended with lithium aluminum hydride $(0.150 \mathrm{~g}, 3.96 \mathrm{mmol})$. The solution was heated at $45^{\circ} \mathrm{C}$ for $4 \mathrm{~h}$. The solution was washed with water, evaporated under reduced pressure and dried in vacuo for several hours to give $0.93 \mathrm{~g}$ of Adl as white crystals. The product was purified by repeated flush column chromatography. Adl: ${ }^{1} \mathrm{H}$ NMR $\left(\mathrm{CDCl}_{3}\right) \delta 1.53$ $\left(6 \mathrm{H}, \mathrm{s}\right.$, adamantyl $\left.\mathrm{CH}_{2}\right), 1.67(6 \mathrm{H}, \mathrm{dd}, J=12,38 \mathrm{~Hz}$, adamantyl $\left.\mathrm{CH}_{2}\right), 1.96(3 \mathrm{H}, \mathrm{s}$, adamantyl $\mathrm{CH}), 2.25(2 \mathrm{H}$, $\mathrm{s}, \mathrm{NH}-\mathrm{CH}_{2}$-adamantyl), $3.80\left(2 \mathrm{H}, \mathrm{s}, \mathrm{Ar}-\mathrm{CH}_{2}-\mathrm{NH}\right)$, 5.22, $5.73\left(2 \mathrm{H}, \mathrm{d}, J=11,18 \mathrm{~Hz}\right.$, vinyl $\left.\mathrm{CH}_{2}\right), 6.71(1 \mathrm{H}$, $\mathrm{dd}, J=11,18 \mathrm{~Hz}$, vinyl $\mathrm{CH}), 7.30(2 \mathrm{H}, \mathrm{d}, J=8 \mathrm{~Hz}, \mathrm{Ar}$ $\mathrm{CH}(\mathrm{C}-2,6)), 7.38(2 \mathrm{H}, \mathrm{d}, J=8 \mathrm{~Hz}, \operatorname{ArCH}(\mathrm{C}-3,5)) .{ }^{13} \mathrm{C}$ NMR $\left(\mathrm{CDCl}_{3}\right) \delta 28.6$ (adamantyl C-3, 5, 7), 37.3 (adamantyl C-4, 6, 10), 41.0 (adamantyl C-1, 2, 8, 9), $54.3\left(\mathrm{NH}-\mathrm{CH}_{2}\right.$-adamantyl), $61.8\left(\mathrm{Ar}-\mathrm{CH}_{2}-\mathrm{NH}\right), 113.5$ $\left(\mathrm{CH}_{2}=\mathrm{CH}\right), 126.4(\mathrm{Ar} \mathrm{C}-3,5), 128.4(\mathrm{Ar} \mathrm{C}-2,6), 136.4$ $\left(\mathrm{CH}_{2}=\mathrm{CH}\right), 136.8(\mathrm{Ar}, \mathrm{C}-1,4)$. IR $\left(\mathrm{KBr}, \mathrm{cm}^{-1}\right) 3068$, 3038, 3016, 2901, 2849, 1630, 1510, 1456, 1360, 1140,
Table I. Radical polymerization of Ad0 and Ad1 ${ }^{\mathrm{a}}$

\begin{tabular}{|c|c|c|c|c|}
\hline \multirow{2}{*}{ Monomer } & \multirow{2}{*}{ Initiator } & Temperature & Conversion $^{\mathrm{b}}$ & \multirow{2}{*}[\eta]{$^{\mathrm{c}}$} \\
\hline & & ${ }^{\circ} \mathrm{C}$ & $\%$ & \\
\hline Ad0 & AIBN & 60 & 58 & 0.309 \\
\hline Ad0 & AIBN & 80 & 73 & 0.276 \\
\hline Ad0 & $\mathrm{ACHCN}^{\mathrm{d}}$ & 120 & 89 & 0.173 \\
\hline Ad0 & $t-\mathrm{BP}^{\mathrm{e}}$ & 120 & 88 & 0.095 \\
\hline Adl & AIBN & 60 & 0 & - \\
\hline Adl & AIBN & 80 & 74 & 0.287 \\
\hline Adl & $\mathrm{ACHCN}$ & 120 & $92^{f}$ & - \\
\hline Ad 1 & $t$-BP & 120 & $\ldots g$ & - \\
\hline
\end{tabular}

${ }^{a}$ Polymerized in bulk for $24 \mathrm{~h}$ under $\mathrm{N}_{2} .[\mathrm{I}]_{0}=3 \mathrm{~mol} \%$. ${ }^{\mathrm{b}}$ Estimated by ${ }^{1} \mathrm{H}$ NMR. ${ }^{\mathrm{c}}$ Intrinsic viscosity. Solvent: benzene, at $25^{\circ} \mathrm{C}$. ${ }^{\mathrm{d}} 1,1^{\prime}$-Azobis(cyclohexanecarbonitrile). ${ }^{\mathrm{e}} \mathrm{Di}$ - $t$-butyl peroxide. ${ }^{\mathrm{f}} \mathrm{Par}$ tially gelled. ${ }^{\mathrm{g}}$ Crosslinked polymer.

$1100,895,856,826 . m / z=281.21 . \mathrm{mp}=31.5^{\circ} \mathrm{C}$.

\section{Radical Polymerization of AdO by AIBN}

Ad0 (300 mg, $1.12 \mathrm{mmol})$ and AIBN (5.5 mg, 0.0337 mmol) were placed in $10 \mathrm{~mL}$ flask with a three-way stopcock and degassed. Polymerization was carried out at a specified temperature under nitrogen atmosphere. The product was dissolved in $2 \mathrm{~mL}$ benzene, purified by repeated precipitations from benzene into methanol, and finally freeze-dried with benzene to give the product polymer.

The radical polymerization of Ad1 and copolymerization with styrene and with MMA was carried out the same as for the polymerization of $\mathrm{Ad} 0$.

\section{RESULTS AND DISCUSSION}

The radical polymerization of Ad0 and of Ad1 was performed by AIBN as an initiator, in bulk for $24 \mathrm{~h}$ under nitrogen. The results are shown in Table I. The polymerization was carried out at $60^{\circ} \mathrm{C}$ to give a white polymer from Ad0, although no polymer was obtained from $\mathrm{Ad} 1$. When polymerization was performed at $80^{\circ} \mathrm{C}$, the polymers were obtained from both monomers. These polymers were soluble in common organic solvents except for hexane and alcohols. The resulting polymers were isolated and purified by repeated reprecipitation, to investigate the structures of the polymers. The IR spectra of poly(Ad0) and poly(Ad1) showed no absorption at $1630 \mathrm{~cm}^{-1}$ from the vinyl groups. The absence of vinyl groups was also confirmed in ${ }^{1} \mathrm{H}$ NMR spectra of the polymers. Figures 1 and 2 show ${ }^{1} \mathrm{H}$ NMR spectra of Ad0, Ad1, and their polymers. Signals of the vinyl group were observed at 5.2, 5.7, and $6.7 \mathrm{ppm}$ in the spectra of the monomers. These signals were not observed in the spectra of the polymers. In the spectra of poly(Ad0) and poly(Ad1), broad signals were observed at $0.6-2.3 \mathrm{ppm}$. These broad signals were attributed to methylene and methine protons of the polymer main chains. Signals were noted at $6.1-7.2,3.5-3.8$, and $1.7-2.1 \mathrm{ppm}$, due to aromatic, benzyl, and methylene and methine protons of the adamantane moiety. Conversion was estimated from the relative intensity of the benzyl protons based on the polymers and monomers. The benzyl protons of the monomers appeared as a sharp singlet signal at $3.8 \mathrm{ppm}$. Observation of the signals of the methylene 

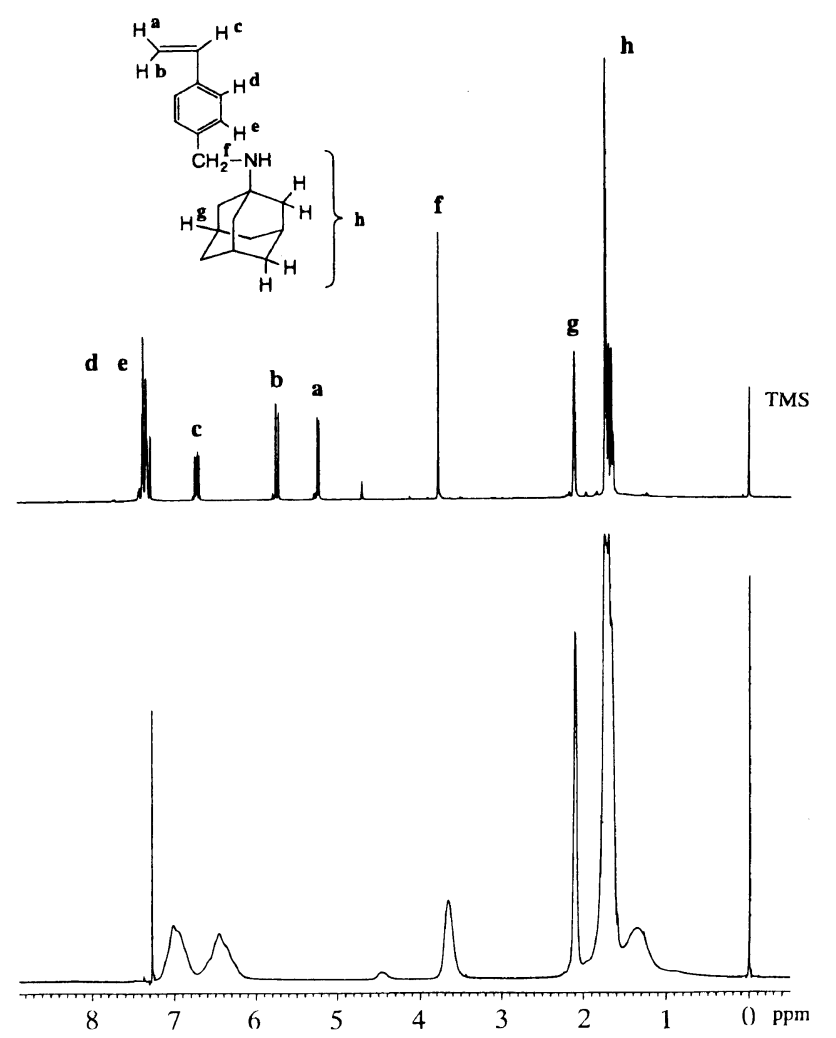

Figure 1. ${ }^{1} \mathrm{H}$ NMR spectra of Ad0 (upper) and poly(Ad0) (lower) (solvent: $\mathrm{CDCl}_{3}$ ).
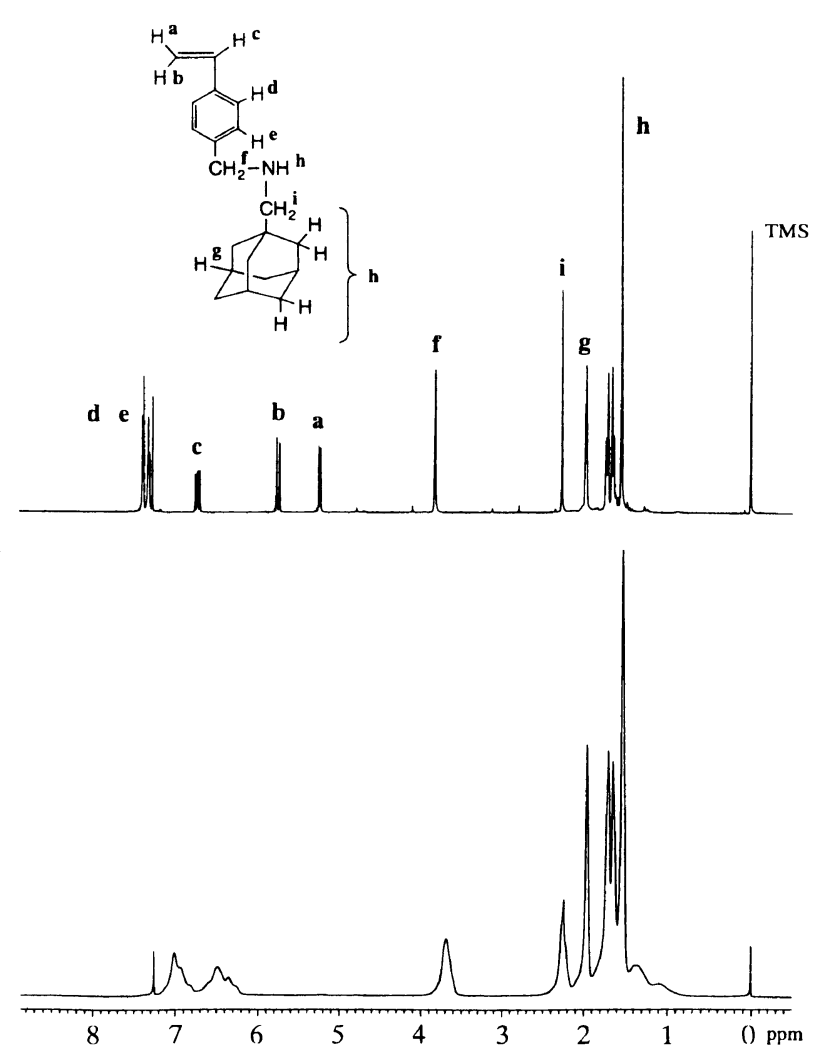

Figure 2. ${ }^{1} \mathrm{H}$ NMR spectra of $\mathrm{Adl}$ (upper) and poly(Ad1) (lower) (solvent: $\mathrm{CDCl}_{3}$ ).

attached to the adamantyl moiety was made at $2.3 \mathrm{ppm}$, in the spectra of Ad1 and poly(Ad1). It was assumed that the polymerization proceeded at the vinyl group, and the relative integral intensity of the respective signals

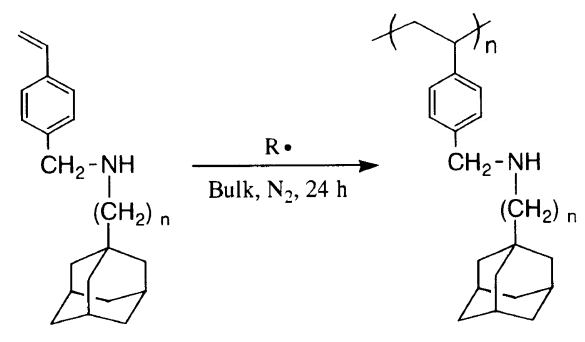

Ad0: $n=0$

Ad1: $n=1$

Scheme 1.

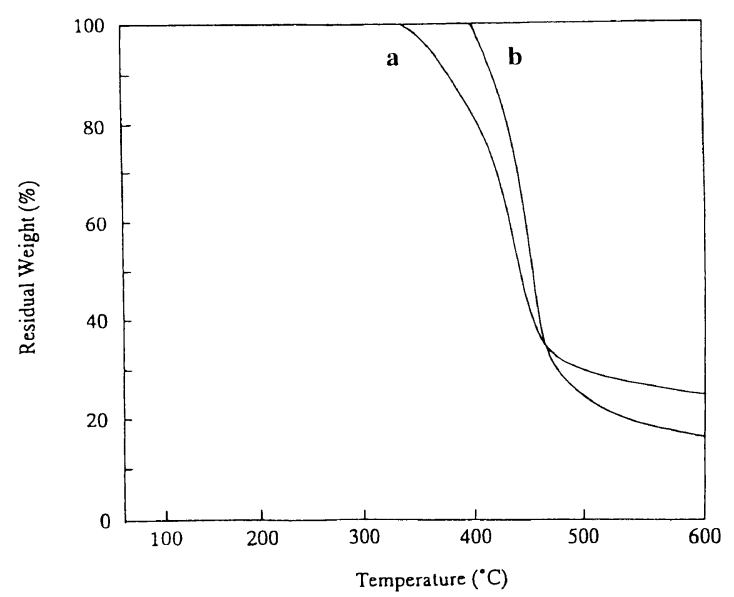

Figure 3. TGA spectra of the poly(Ad0) (a) and the poly(Ad1) (b) obtained by polymerization at $80^{\circ} \mathrm{C}$.

was in a good agreement with the theoretical one. It can be deduced that the adamantyl moieties did not participate the polymerization at all, and that the synthesis of the polymers with adamantane amino derivatives as pendant groups was attained (Scheme 1). When the polymerization was performed at $120^{\circ} \mathrm{C}$ by $1,1^{\prime}$-azobis(cyclohexane carbonitrile) as the initiator, a benzene-soluble polymer was obtained from Ad0, while a partially crosslinked polymer was generated from Ad 1 . The polymerization of Adl was carried out using di$t$-butyl peroxide at $120^{\circ} \mathrm{C}$ to give a completely crosslinked polymer. This indicates that the crosslinking reaction more easily occurs in the polymerization of Ad1 than in that of Ad0. This can be accounted for by the fact that the methylene spacer attached to the adamantyl group diminishes steric hindrance of this group, at the benzyl position, so that crosslinkage easily occurs by coupling between benzyl radicals. Molecular weights and polydispersities of the resulting polymers could not be calculated by GPC, because the polymers were adsorbed in the polystyrene gel columns used with THF as an eluent. Therefore, the intrinsic viscosity of the polymers was determined with benzene as the solvent. It is clear that steric hindrance of the adamantyl group prevents the polymerization from proceeding. This is because poly(4-aminomethylstyrene) and poly(4-aminoethylstyrene) obtained by radical polymerization in bulk at $80^{\circ} \mathrm{C}$ had much higher viscosity than that of poly(Ad0) and poly(Ad1). ${ }^{10}$

The thermal stability of poly(Ad0) and poly(Ad1) was excellent based on TGA analysis. As seen in Figure 3, poly(Ad0) shows a $10 \%$ weight loss at $380^{\circ} \mathrm{C}$, while 


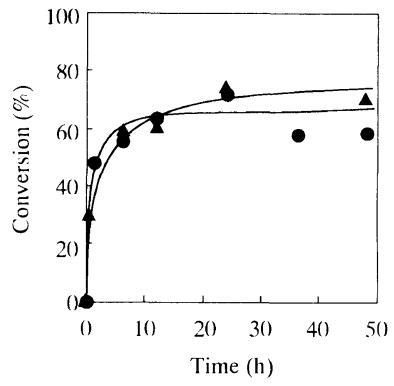

Figure 4. Time-conversion plots in the polymerization of Ad0 (C) and of Adl (A). Polymerized in bulk at $80^{\circ} \mathrm{C}$ under $\mathrm{N}_{2}$. $[\mathrm{AIBN}]_{0}=3 \mathrm{~mol} \%$

Table II. Copolymerization of Ad and styrene ${ }^{a}$

\begin{tabular}{|c|c|c|c|c|c|c|c|}
\hline \multirow{2}{*}{ Monomer } & \multicolumn{2}{|c|}{ Feed ratio } & \multicolumn{2}{|c|}{ Conversion $/ \%$} & \multicolumn{2}{|c|}{ Ratio in copolymer ${ }^{b}$} & \multirow{2}{*}[\eta]{$^{\mathrm{d}}$} \\
\hline & $\mathrm{Ad}$ & $\mathrm{St}$ & $\mathrm{Ad}^{\mathrm{b}}$ & $\mathrm{St}^{\mathrm{c}}$ & $\mathrm{Ad}$ & St & \\
\hline Ad0 & 0.10 & 0.90 & 97 & 97 & 0.11 & 0.89 & 0.402 \\
\hline Ad0 & 0.20 & 0.80 & 94 & 95 & 0.20 & 0.82 & 0.446 \\
\hline Ad0 & 0.33 & 0.67 & 95 & 89 & 0.31 & 0.69 & 0.424 \\
\hline Ad0 & 0.50 & 0.50 & 77 & 91 & 0.45 & 0.55 & 0.395 \\
\hline Ad0 & 0.67 & 0.33 & 88 & 87 & 0.60 & 0.40 & 0.394 \\
\hline Ad0 & 0.80 & 0.20 & 93 & 88 & 0.77 & 0.23 & 0.295 \\
\hline Ad0 & 0.90 & 0.10 & 84 & 82 & 0.81 & 0.19 & 0.366 \\
\hline Adl & 0.10 & 0.90 & 98 & 97 & 0.08 & 0.92 & 0.421 \\
\hline Adl & 0.20 & 0.80 & 99 & 95 & 0.18 & 0.82 & 0.401 \\
\hline Adl & 0.33 & 0.67 & 96 & 90 & 0.28 & 0.72 & 0.434 \\
\hline Ad1 & 0.50 & 0.50 & 98 & 90 & 0.51 & 0.49 & 0.381 \\
\hline Adl & 0.67 & 0.33 & 88 & 79 & 0.59 & 0.41 & 0.323 \\
\hline Ad1 & 0.80 & 0.20 & 93 & 88 & 0.70 & 0.30 & 0.319 \\
\hline Adl & 0.90 & 0.10 & 86 & 80 & 0.79 & 0.21 & 0.263 \\
\hline
\end{tabular}

${ }^{a}$ Polymerized in bulk by AIBN at $80^{\circ} \mathrm{C}$ for $48 \mathrm{~h}$. [AIBN] $]_{0}=$ $3 \mathrm{~mol} \%$. ${ }^{\mathrm{b}}$ Estimated by ${ }^{1} \mathrm{H}$ NMR. $\quad{ }^{\mathrm{c}}$ Calculated by GC. ${ }^{\mathrm{d}}$ Intrinsic viscosity. Solvent: benzene, at $25^{\circ} \mathrm{C}$.

poly(Ad1) shows that at $420^{\circ} \mathrm{C}$. It is clear that this high stability of poly(Ad1) is caused by the presence of the methylene group attached to the adamantyl moiety. This can be accounted for by the fact that the methylene spacer has the potential to reduce interactions between adamantyl moieties in the polymer.

Time-conversion plots in the polymerization of Ad0 and of Ad1 are shown in Figure 4. The polymerization was carried out by $\mathrm{AIBN}$ at $80^{\circ} \mathrm{C}$. The conversion reached ca. $60 \%$ in $6 \mathrm{~h}$, and then leveled off in both cases. The reactivity of Ad0 and Adl was thus not so high, and that this low reactivity is caused by the steric hindrance between the adamantyl groups attached to the growing chain end and to the monomer. One reason for the low reactivity may also be that the polymers have low solubility in monomers. This is because the polymers precipitated during the polymerization over ca. $50 \%$ of the conversion. It is expected that the conversions increase in the copolymerization with monomers in which poly(Ad0) and poly(Ad1) easily dissolved. The copolymerizations of $\mathrm{Ad} 0$ and of $\mathrm{Adl}$ with styrene were performed by AIBN in bulk at $80^{\circ} \mathrm{C}$ for $48 \mathrm{~h}$. The results are summarized in Table II. As expected, the conversions of the monomers reached over $80 \%$ in all cases. The viscosity of the copolymer decreased as a result of increase in the monomer. The ratios of $\operatorname{Ad} 0$ and $\operatorname{Ad} 1$ to styrene units in the copolymers were estimated by ${ }^{1} \mathrm{H}$

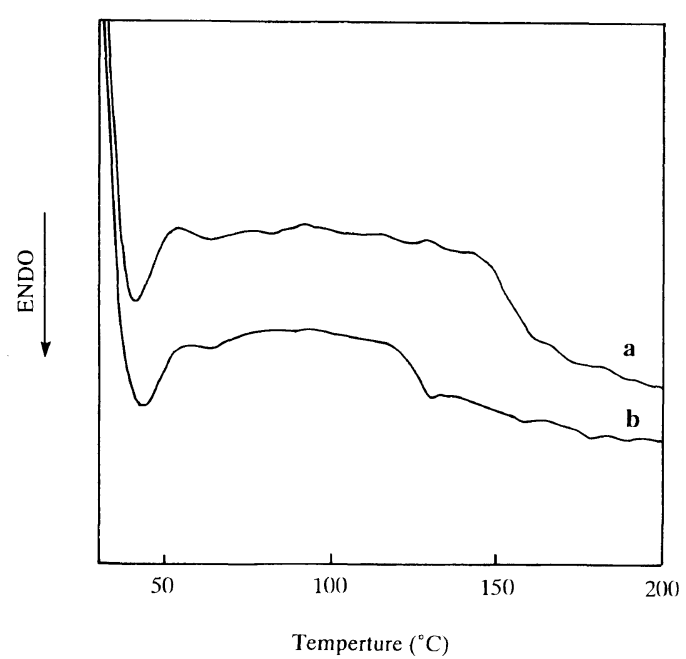

Figure 5. DSC spectra of the poly(Ad0-styrene) $(\mathbf{a}, \mathrm{Ad} 0 /$ styrene $=$ $45 / 55)$ and the poly(Adl-styrene) $(\mathbf{b}, \mathrm{Adl} / \mathrm{St}=51 / 49)$.

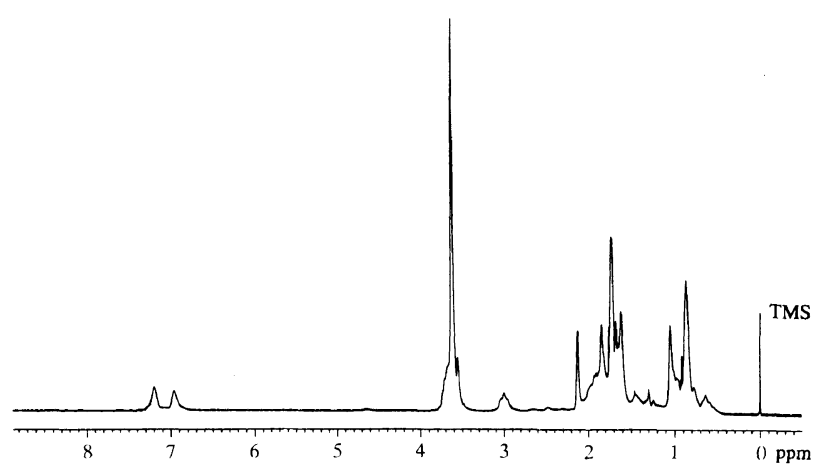

Figure 6. ${ }^{1} \mathrm{H}$ NMR spectrum of the poly(Ad0-MMA) (solvent: $\mathrm{CDCl}_{3}$ ).

NMR, and were in a good agreement with the feed ratios of the monomers. The random copolymers were obtained, because DSC analysis demonstrated that the copolymers had only one $T_{\mathrm{g}}$ between those of the homopolymers (Figure 5). The copolymer in which the ratio of Ad0 to styrene units was $45 / 55$ showed $T_{\mathrm{g}}$ at $147^{\circ} \mathrm{C}$, while the homopolymer of Ad0 had that at $165^{\circ} \mathrm{C}$. The poly(Ad1-styrene) $(\mathrm{Ad} 1 /$ styrene $=51 / 49)$ also had one $T_{\mathrm{g}}$ at $119^{\circ} \mathrm{C}$, and poly(Ad1) showed this at $125^{\circ} \mathrm{C}$. Polystyrene obtained by polymerization with AIBN at $80^{\circ} \mathrm{C}$ showed $T_{\mathrm{g}}$ at $90^{\circ} \mathrm{C}$. We deduced that the random copolymers were obtained.

The copolymerizations of monomers with MMA were carried out at feed ratios of the monomers to MMA of $10 / 90$. The polymerization was performed by AIBN at $80^{\circ} \mathrm{C}$ for $1 \mathrm{~h}$ to give white polymers. The copolymers of Ad0 and of Ad1 had molecular weights of 7500 and 16200 , and polydispersities of 1.77 and 2.36 , respectively. These molecular weights and polydispersities were estimated by GPC calibrated with polystyrene standards. The copolymers obtained showed signals originating from the monomers and MMA, in the ${ }^{1} \mathrm{H}$ NMR spectra (Figure 6). The ratios of the monomers to MMA units in the copolymers were estimated as 14/86 for poly(Ad0-MMA), and to be 22/78 for poly(Ad1-MMA), based on the relative intensity of the aromatic protons of $\mathrm{Ad} 0$ and $\mathrm{Ad} 1$, to the protons observed at $3.4-3.9 \mathrm{ppm}$. These protons originate from the methylene of $\mathrm{Ad} 0$ and 
Ad1 units and methoxy protons of MMA units. The DSC spectra demonstrated that the random copolymers were obtained, because the copolymers each had one $T_{\mathrm{g}}$ at $127^{\circ} \mathrm{C}$ for poly(Ad0-MMA), and at $118^{\circ} \mathrm{C}$ for poly(Ad1-MMA).

Study on bioactivity of poly(Ad0), poly(Ad1), and their copolymers is in progress.

\section{CONCLUSION}

The radical polymerization of Ad0 and of Ad1 proceeded at vinyl groups to give polymers with adamantane amino derivatives as pendant groups. The reactivity of the monomers was not so high. The polymerization of Ad0 gave polymers without crosslinked products, and the copolymers were completely soluble in several organic solvents. Remarkable effect of temperature was observed on the polymerization of Ad1. In particular, the polymerization of Ad 1 at $120^{\circ} \mathrm{C}$ produced a crosslinked polymer. This indicates that crosslinking occurs more easily in the polymerization of Ad1 than Ad0, because the methylene spacer diminishes steric hindrance of the adamantyl group, at the benzyl position. This methylene spacer contributed to the thermal stability of poly(Ad1). The conversions of Ad0 and Adl leveled off in the polymerization in bulk at $80^{\circ} \mathrm{C}$, due to low solubility of the polymers in the monomers. The conversions reached over $80 \%$ in copolymerization with styrene. The copolymerization gave the corresponding random copolymers in which the ratios of the monomers to styrene units were essentially the same as the feed ratios.

\section{REFERENCES}

1. M. Nomura, M. Kyouda, T. Hirokawa, Y. Fujiwara, and M. Sugiura, Nippon Nōgeikagaku Kaishi, 68, 973 (1994).

2. M. Kaji and H. Shoji, Naika, 49, 679 (1982).

3. R. S. Schwab, A. C. England, Jr., D. C. Poskanzer, and R. R. Young, J. Am. Med. Ass., 208, 1168 (1969).

4. K. W. Cochran and H. F. Maassab, Fed. Proc., Fed. Am. Soc. Exp. Biol., 23, 387 (1964).

5. N. Oker-Blom and A. L. Anderson, Eur. J. Cancer, 2, 9 (1966).

6. A. M. Wallbank, R. E. Matter, and N. G. Klinikowski, Science, 152, 1760 (1966).

7. K. Sugita and K. Kinoshita, Kinki Daigaku Kougakubu Kenkyuhokoku, 18, 27 (1984).

8. M. Nomura, S. Shintani, Y. Fujiwara, M. Sugiura, S. Takagi, and M. Yamamoto, Nippon Nōgeikagaku Kaishi, 70, 453 (1996).

9. W. J. Dale, L. Starr, and C. W. Strokel, J. Org. Chem., 26, 2225 (1961).

10. A. T. Mkrtchian, G. H. Zhamkochian, and G. M. Poghossian, Arm. Khim. Zh., 27, 974 (1974). 